\title{
Stepwise Decreasing of Vitreous Pressure by Anterior Vitrectomy: A Novel Method for Preventing Positive Vitreous Pressure During Penetrating Keratoplasty
}

\author{
Xinyu Huang · Qi Zhou · Sangsang Wang · Juan Zhang • \\ Guozhen Niu • Yanlong Bi
}

Received: September 2, 2019 / Published online: November 15, 2019

(c) The Author(s) 2019

\begin{abstract}
Background: This study evaluates the clinical effects of the stepwise anterior vitrectomy on the prevention of positive vitreous pressure (PVP) during penetrating keratoplasty (PKP).

Methods: PKP in conjunction with stepwise anterior vitrectomy was performed on 15 eyes of 15 patients under retrobulbar anesthesia. A preset vitrectomy trocar-cannula was inserted into the vitreous cavity before PKP. During the opening of the anterior chamber, intermittent vitrectomy and corneal incision expansion were performed alternately to keep the lens or artificial intraocular lens (IOL) and iris flat until the entirety of the pathological cornea had been dissected. The main outcome measures include visual acuity, crystalline lens rise (CLR), corneal curvature and diopter, and corneal endothelial cell loss.
\end{abstract}

Enhanced Digital Features To view enhanced digital features for this article go to https://doi.org/10.6084/ m9.figshare.9982574.

X. Huang · Q. Zhou - S. Wang · J. Zhang - G. Niu · Y. Bi (ه)

Department of Ophthalmology, Tongji Hospital Affiliated with Tongji University School of

Medicine, Shanghai 200065, People's Republic of

China

e-mail: biyanlong@tongji.edu.cn
Results: All surgical procedures were performed successfully without any PVP-related intraoperative complications. The mean time of the stepwise vitrectomies was $3.1 \pm 0.7 \mathrm{~s}$, the duration of each vitrectomy was $8.1 \pm 5.3 \mathrm{~s}$, and the duration of the total surgery was $60.5 \pm 5.3 \mathrm{~min}$. The anterior segment reaction was mild and the shape of the pupil remained normal 1 day after surgery. The mean preoperative and mean 3-month postoperative CLR values were $0.48 \pm 0.09 \mathrm{~mm}$ and $-0.16 \pm 0.04 \mathrm{~mm}$, respectively $(p<0.0001)$. The mean preoperative endothelial cell density in donor buttons was $2570 \pm 171$ cells $/ \mathrm{mm}^{2}$, and the mean 6- and 12-month postoperative endothelial cell density in donor buttons was $2207 \pm 127$ cells $/ \mathrm{mm}^{2}$ and $2000 \pm 198$ cells/ $\mathrm{mm}^{2}$, respectively.

Conclusions: The novel and stabilized PKP procedure, performed in conjunction with the stepwise anterior vitrectomy, effectively avoided the PVP during open-sky surgery.

Trial Registration: Chinese Clinical Trial Registry, ChiCTR1900021227.

Keywords: Endothelial cell loss; Ophthalmology; Penetrating keratoplasty; Positive vitreous pressure; Vitrectomy 


\section{Key Summary Points}

Why carry out this study?

Penetrating keratoplasty (PKP) has since the mid-1950s been the main therapeutic method for keratopathy, which causes blindness. Although selective lamellar keratoplasty has developed rapidly during the past decade, PKP is still an important corneal transplantation procedure and the best choice for treating full-thickness corneal disease like corneal leucoma, Fuchs' corneal dystrophy, keratoconus, and so on.

PKP is an open-sky surgery that carries a high risk of intraoperative complications caused by positive vitreous pressure (PVP), which might cause severe intraoperative and postoperative complications such as blindness. To avoid the PVP during opensky surgery and fundamentally increase surgical safety, we designed this novel and stabilized PKP procedure. This study mainly introduces a novel and stabilized PKP procedure.

\section{What was learned from the study?}

This novel and stabilized PKP procedure, which was performed in conjunction with the stepwise anterior vitrectomy, could become an alternative corneal transplantation procedure. All demographic data, examination results, and figures of the surgery procedure are shown in the paper.

PVP is particularly common during open anterior segment surgery. This novel and stabilized PKP procedure could effectively avoid the PVP during open-sky surgery.

First of all, for stepwise anterior vitrectomy being performed during the open-sky surgery, the risk of PVP happening is quite low. However, if the novel procedure we propose was not that effective or PVP still happened during the open-sky surgery, then more methods should be applied for controlling risk factors of PVP that can be modified, such as minimizing the degree and duration of ocular hypotony during intraocular surgery, minimizing the absolute intraocular pressure drop during open surgery, controlling systemic risk factors, and preventing external globe compression.

\section{INTRODUCTION}

Since the mid-1950s, penetrating keratoplasty (PKP) has been the main therapeutic method for keratopathy, which causes blindness [1]. Although selective lamellar keratoplasty has developed rapidly during the past decade [2], PKP remains an important corneal transplantation procedure and the best choice for treating full-thickness corneal disease. It was reported that during the 10-year period from 2002 to 2011, 86.5\% (4191) of all corneal transplantations performed in the UK, Columbia, and Canada were PKP procedures [3]. In the USA, this number decreased from $95 \%$ to $42 \%$ $(19,535$, i.e., $42 \%$ of 46,513 transplants) in the past 10 years, but this was still a large number [4].

PKP is an open-sky surgery that carries a high risk of intraoperative complications, such as acute suprachoroidal effusion or hemorrhage, dislocation or prolapse of intraocular contents (iris, lens, or vitreous) (Fig. 1), iris or lens damage, and cystoid macular edema. The first two of these complications, which are secondary to positive vitreous pressure (PVP), are considered the most severe $[1,5]$. Recent research has partly clarified the pathogenesis and pathophysiology of PVP, and it has identified hypotony resulting from aqueous loss as the fundamental reason for PVP [5].

In this study, we designed a novel and stabilized PKP procedure that can be performed safely under retrobulbar anesthesia, using microinvasive anterior segment vitrectomy to prevent intraoperative PVP. 

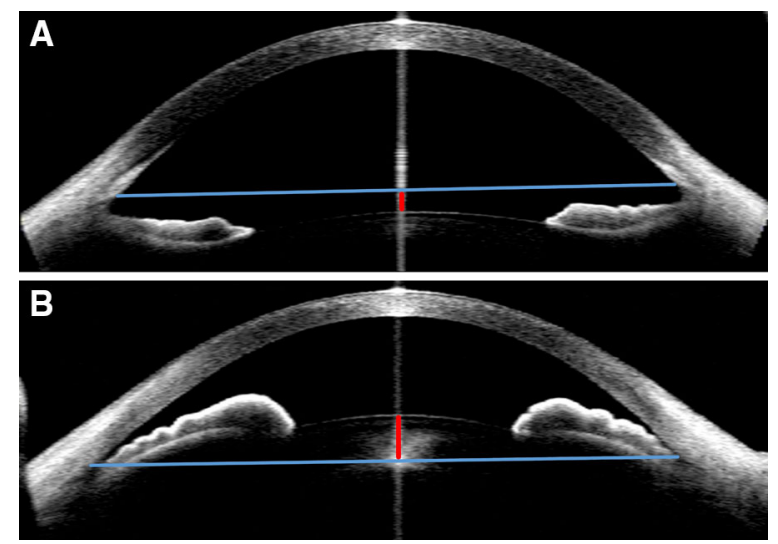

Fig. 1 An anterior segment optical coherence tomography (AS-OCT) image of an anterior segment with different depths. The blue line represents the anterior chamber width $(\mathrm{ACW})$, which connects the two scleral spurs. The red line represents the crystalline lens rise (CLR), which is the vertical dimension between the anterior surface of the lens and the ACW. a The position of the ACW is higher than that of the anterior surface of the lens, so the CLR is negative. $\mathbf{b}$ The position of the ACW is lower than that of the anterior surface of lens, so the CLR is positive

\section{METHODS}

This study was a retrospective noncomparative case series in which the new procedure of using PKP in conjunction with stepwise anterior vitrectomy was performed on 15 eyes of 15 patients between May 2016 and April 2017 at the Department of Ophthalmology, which is affiliated with the Tongji University School of Medicine. This study was approved by the ethics committee of Tongji Hospital, Tongji University School of Medicine, and adhered to the tenets of the Declaration of Helsinki. Written informed consent was obtained from the patients for publication of this article and any accompanying images. All procedures were performed by the same experienced surgeon (Yanlong Bi). The inclusion criteria were patients with full-thickness or deep corneal disease that had led to corneal opacities that impair vision, such as corneal leucoma with or without intraocular lens (IOL) implantation, chronic bullous keratopathy, and acute corneal hydrops caused by keratoconus. The exclusion criteria were patients with a history of vitrectomy, vitreoretinopathy, active infectious keratitis, and uncontrolled intraocular pressure, as well as patients with severe systemic disease who could not tolerate surgery.

Several ophthalmic examinations were performed before and after surgery. These included the best corrected visual acuity (BCVA) test, intraocular pressure (IOP) test, slit-lamp examination, endothelial cell density (ECD) examination, refractive error measurement (corneal topography), and B-scan ultrasonography. The refractive error measurement was analyzed by computer-assisted corneal topography (TOPCON, Japan). The anterior chamber width (ACW) and crystalline lens rise (CLR) of patients with the lens were measured using anterior segment optical coherence tomography (ASOCT; Carl Zeiss Meditec, USA). The ACW is the length of the connecting line between the two scleral spurs; it can be measured by horizontal scanning using AS-OCT. The CLR is the vertical dimension between the anterior surface of the lens and the ACW. If the position of the former is higher than that of the latter, the CLR will be a positive number; if it is lower, the CLR will be a negative number (Fig. 1).

Statistical analysis was performed using SPSS version 13.0 (SPSS Inc., IBM, USA), and the results are expressed as the mean \pm the standard deviation (SD). A paired samples $t$ test was used to test the preoperative and postoperative ACW and CLR, with a $p$ value of less than 0.05 $(p<0.05)$ considered statistically significant.

\section{Surgical Procedure}

The eye undergoing surgery was compressed moderately by the surgeon $5 \mathrm{~min}$ after the induction of retrobulbar anesthesia (1:1 mixture of $2 \%$ lidocaine and $0.75 \%$ bupivacaine) to soften the eyeball and reduce the intraocular pressure. A preset trocar-cannula system was inserted into the vitreous cavity through the bulbar conjunctiva at the pars plana at the $11 \mathrm{o}^{\prime}$ clock position, at a distance of $3.5 \mathrm{~mm}$ (in an aphakic and a pseudophakic eye) or $4.0 \mathrm{~mm}$ (in a phakic eye) from the limbus (Fig. 2a, b). To prevent vitreous loss and to maintain the IOP, 




Fig. 2 Stages in penetrating keratoplasty assisted by stepwise anterior vitrectomy. a, b The placement of a preset vitrectomy trocar-cannula. c The recipient cornea was trephined using a vacuum trephine. $\mathbf{d}$, e The opening of the anterior chamber. $\mathbf{f}$ An anterior vitrectomy was performed to reduce the vitreous pressure. $\mathrm{g}$ A temporary interrupted suture was adopted at the incisional segment to maintain the corneal topography. $\mathbf{h}-\mathbf{l}$ The extending of the corneal penetrating incision and the laying of the sutures. m An anterior vitrectomy was performed to reduce the vitreous pressure. During the procedure, a vitrectomy, a cutting of residual cornea, and an injection of viscoelastic material were performed successively. $\mathbf{n}$ The removal of all temporary sutures. o After the removal of the fullthickness recipient button, the intraocular contents were in stable condition. $\mathbf{p}, \mathbf{q}$ The donor cornea button was placed along the recipient corneal rim, and interrupted sutures were placed between the donor cornea button and the recipient corneal rim with $10-0$ nylon thread. $\mathbf{r}$ Sixteen interrupted corneal sutures and two interrupted scleral sutures were applied 

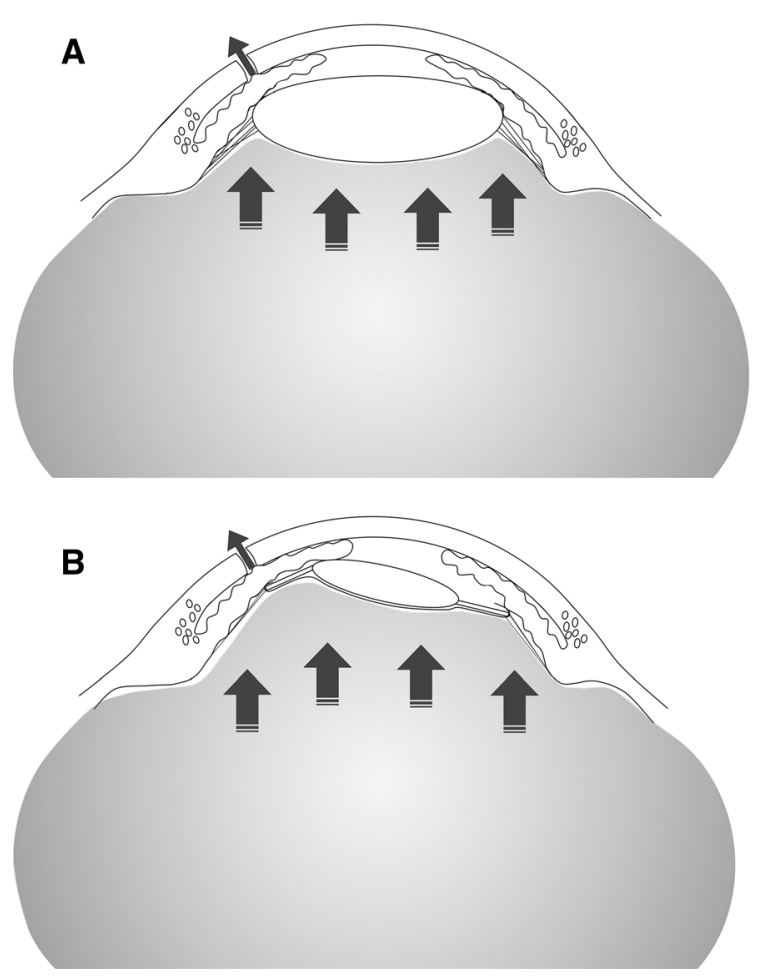

Fig. 3 Schematic drawings of four different conditions during PKP. a The occurrence of PVP during PKP. The anterior chamber was opened, and the pressure of the anterior chamber was reduced suddenly to $0 \mathrm{mmHg}$. The difference in pressure between the vitreous cavity and the anterior chamber could push the intraocular contents out and cause a hernia of the iris and vitreous. $\mathbf{b}$ PVP may be

the trocar was sealed before the PKP procedure was begun.

The recipient cornea was trephined to a thickness of about $80 \%$ using a vacuum trephine (Medin-ural, Russia) with a diameter ranging from 7.5 to $8.75 \mathrm{~mm}$, which was at least $0.25 \mathrm{~mm}$ larger than that of the primary lesion (Fig. 2c). A sharp-tipped $15^{\circ}$ blade or a curved corneal scissor approximately $3.0 \mathrm{~mm}$ wide was then used to penetrate the incision at the 11 o'clock position; and at this time, the aqueous flowed out (Fig. 2d, e). If the patient had serious PVP, the iris could prolapse and bulge from this corneal incision gap. Because the width of the gap was only $3.0 \mathrm{~mm}$, the prolapsed iris could usually be easily pushed into

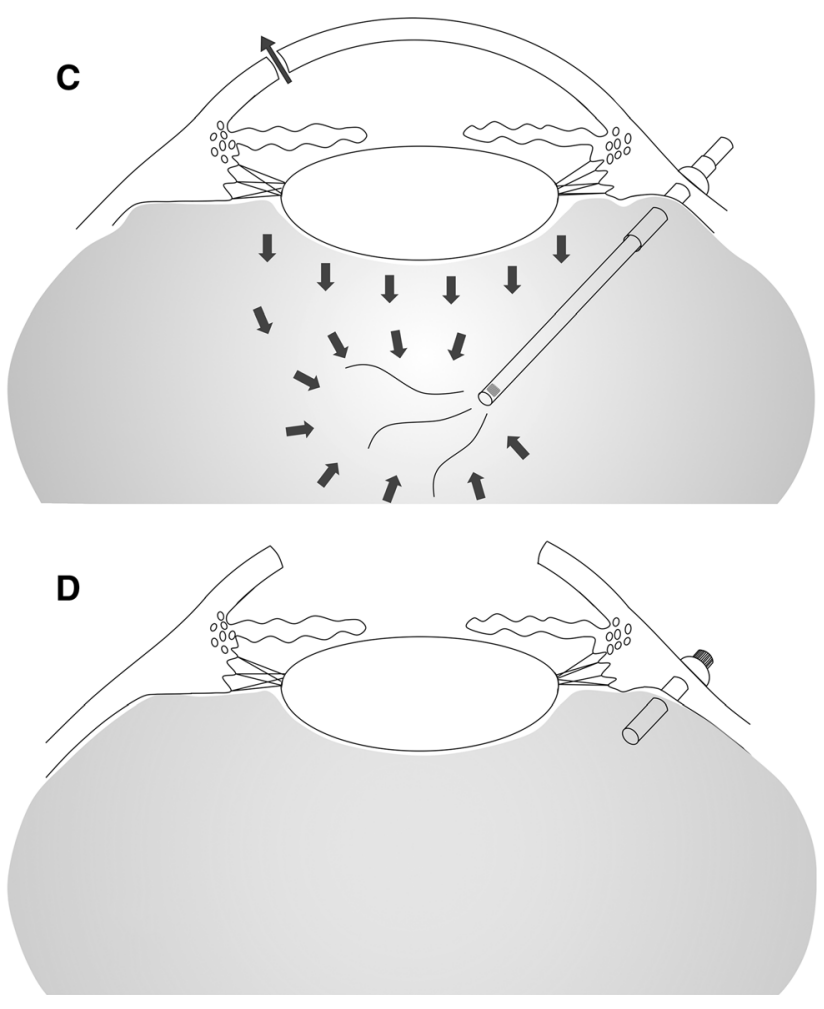

more serious in patients with IOL during PKP. c The stepwise microinvasive anterior vitrectomy is begun; the pressure of the vitreous cavity is reduced; and the iris, lens-iris diaphragm, and lens are in the correct position. d After the removal of the full-thickness recipient button, the intraocular contents are in the correct position

the anterior chamber using viscoelastic material (Fig. 3a, b).

The vitrectomy cutter was then immediately inserted vertically $6-10 \mathrm{~mm}$ into the center of the vitreous cavity through a preset trocar (Fig. 2f). To reduce the vitreous pressure, the vitrectomy was performed stepwise and gradually at a cut rate of 1500 cuts per min and a linear aspiration power of $50-100 \mathrm{mmHg}$ (Figs. 2f, $\mathrm{m}$ and 3c). A sharp-tipped $15^{\circ}$ blade and curved corneal scissors were used to dissect the recipient button along the trephination groove, with viscoelastic material constantly injected to flatten the bulged iris and maintain the anterior chamber (Fig. 2h, i). In this step, the surgeon should observe the position of the lens-iris diaphragm to evaluate the vitreous 
pressure in order to determine whether the intermittent vitrectomy should be restarted and to what extent the vitreous should be excised. The indication for performing the intermittent vitrectomy was the bulge of the iris, and the procedure ended once the iris had returned to the correct position. The incision was further extended by approximately $3 \mathrm{~mm}$. The stabilization of the vitreous pressure was again evaluated, and the intermittent vitrectomy process was sometimes repeated. After one quarter of the cornea had been dissected, a temporary interrupted suture was applied to the middle of the incisional segment (Fig. $2 g, j, 1$ ). Vitrectomy, residual cornea dissection, and viscoelastic material injection were performed successively to ensure the stabilization of the iris and lens. Excessive vitrectomy should be avoided to prevent the eyeball from collapsing, and the trocar lid should be put back every time the vitrectomy is stopped in order to prevent excessive vitreous loss.

After all the connections between the recipient button and recipient corneal rim had been dissected and four temporary interrupted sutures had been simultaneously applied, the preparation of the donor cornea began. The donor cornea button, which was $0.25 \mathrm{~mm}$ larger than the recipient graft site, was trephined from the endothelial side of a fresh donor cornea. The temporary interrupted sutures and fullthickness recipient button were then carefully removed (Figs. 2n, o and 3d), and the donor cornea button was placed along the recipient corneal rim and sutured with 10-0 nylon thread (Figs. 2p, q). The trocar-cannula was withdrawn, and the scleral incision was closed with the $10-0$ nylon thread as well (Fig. 2r). The sutures were removed 1 week after surgery.

\section{RESULTS}

This novel procedure was performed on 15 eyes of 15 patients without any intraoperative complications, such as acute suprachoroidal effusion or hemorrhage, iris or lens prolapse or damage, or cystoid macular edema. In addition, none of the patients developed a postoperative high IOP or endophthalmitis. In each procedure, the mean time of the stepwise vitrectomies was $3.1 \pm 0.7 \mathrm{~s}$, and the duration of each vitrectomy was $8.1 \pm 5.3 \mathrm{~s}$. The duration of the entire surgical procedure was $60.5 \pm 5.3 \mathrm{~min}$.

Out of all the cases, one patient with an old corneal leucoma experienced graft endothelial rejection in one eye. It was diagnosed by the presence of an endothelial rejection line with concomitant corneal edema 6 weeks after surgery. This was treated with topical steroid therapy (topical fluoroquinolone and topical steroids, tobramycin dexamethasone eye drops) taken each waking hour for 1 week and a 40-mg peribulbar methylprednisolone injection administered once daily for three consecutive days. After the topical steroid medication had been used, the progression was controlled and reversed.

There were two cases of pseudophakia. Examination by slit lamp and AS-OCT after surgery revealed that the shapes of the pupils had remained normal (i.e., as they had been before surgery) and that the patients' IOLs were properly located. The mean preoperative value of the ACW was $11.55 \pm 0.28 \mathrm{~mm}$, and the postoperative value after 3 months was $11.52 \pm 0.31 \mathrm{~mm}(p=0.17)$. The mean preoperative CLR value was $0.48 \pm 0.09 \mathrm{~mm}$, and the postoperative value after 3 months was $-0.16 \pm 0.04 \mathrm{~mm}(p<0.0001)$. After all the corneal sutures were removed, the mean postoperative corneal topographic astigmatism was $3.59 \pm 0.98$ diopters (D). The mean endothelial cell density value in donor buttons was $2570 \pm 171$ cells $/ \mathrm{mm}^{2}$; the mean endothelial cell density value was $2207 \pm 127$ cells $/ \mathrm{mm}^{2}$ and $2000 \pm 198$ cells $/ \mathrm{mm}^{2}$ during 6-month and 12 -month postoperative visits, respectively. The endothelial cell loss was $22.2 \% 12$ months after surgery. The anterior segment reaction was mild under the slit-lamp microscope 1 day after surgery, and neither the keratic precipitate nor the Tyndall effect appeared. An OCT examination showed that none of the patients exhibited macular- or surgery-related retinopathy. All demographic data and examination results are shown in Table 1. 







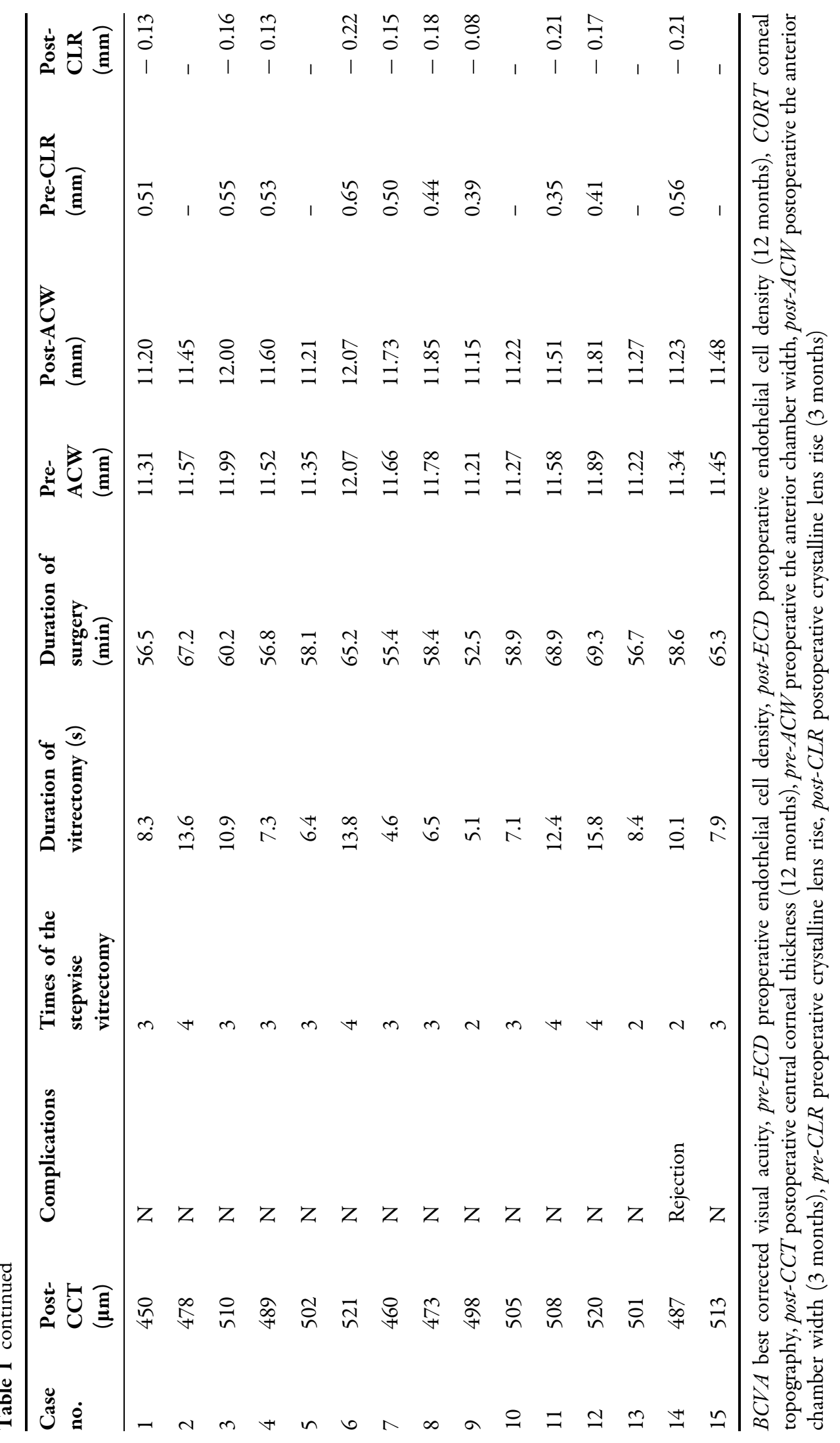




\section{DISCUSSION}

PVP is particularly common during open anterior segment surgery, and it has been reported that during PKP, the incidence rate of PVP is $40-50 \%$ [5]. The rate could be higher if the surgical patient has an underlying disease, such as iris atrophy, pathological pupil, pseudophakic eyes with broken capsular bags, or an undesirable cataract surgery with some parts of the IOL located outside the capsular bag [6].

Acute hypotony resulting from an open-sky surgery is the fundamental cause of intraoperative PVP [5]. When an open anterior chamber surgery starts, the vitreous cavity begins to undergo gradually increasing pressure related to the vitreous cavity volume reduction, and this can be caused by the external compression of the globe or intraoperative acute intraocular intumescence [5]. When the aqueous loss and hypotony occur simultaneously, a difference arises between the pressure in the vitreous cavity and that in the anterior chamber, so that the pressure in the former, which will be significantly higher than that in the latter, pushes the contents of the vitreous cavity forward (Figs. 3a and 4a), even causing lens dislocation $[7,8]$ (Figs. $3 \mathrm{~b}$ and $4 \mathrm{~b}, \mathrm{c}$ ). More importantly, if there is an acute drop in intraoperative IOP, the transmural pressure will increase and rupture the vessels, and the blood will flow into the choroid. The most devastating complicationsuprachoroidal hemorrhage-will ensue, and this condition leads to a very poor prognosis $[9,10]$. To avoid a decrease of vitreous cavity volume and an occurrence of choroidal hemorrhage, inducing general anesthesia and keeping the patient's head tilted upwards are highly recommended $[11,12]$. However, in developing countries, in order to meet the urgent needs of increased patient volume while maintaining economic frugality, local anesthesia has been preferred in ophthalmic surgery $[13,14]$. In our case series, the cost of anterior vitrectomy and local anesthesia is less than the cost of general anesthesia and postoperative nursing. Considering the serious consequences of PVP, several modified PKP methods that can be performed under local anesthesia, such as relatively closed
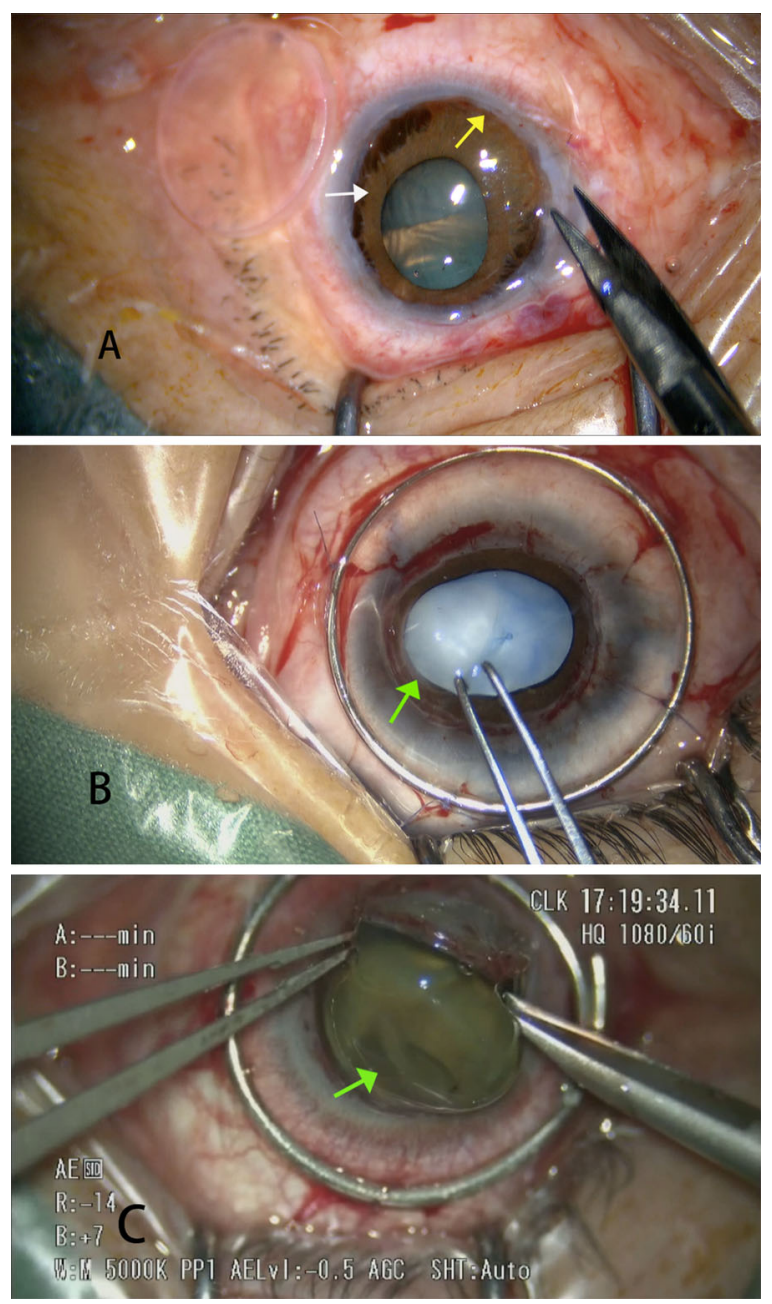

Fig. 4 The occurrence of PVP during PKP under different types of anesthesia. a Under general anesthesia, when the anterior chamber was opened, the intraocular contents were pushed (white arrow) and the anterior chamber angle almost disappeared (yellow arrow). b, c Under retrobulbar anesthesia, when the anterior chamber was opened, lens dislocation occurred (green arrow)

anterior chamber techniques or minimizing the degree and duration of an open-sky procedure, have been proposed $[11,15,16]$. The preoperative use of an intravenous diuretic, such as mannitol or acetazolamide, to decrease the vitreous volume has also been advocated [8]. Currently, vitrectomy is extensively used in combination with anterior segment disease surgery, such as phacoemulsification in angleclosure glaucoma [17], and a review [18] reported that most of the changes in the anterior 
segment after uncomplicated pars plana vitrectomy (PPV) are found to be temporary. To maintain the stability of the anterior chamber and avoid PVP, we combined PKP and microinvasive vitrectomy. The technique we presented here is an alternative method that not only could avoid PVP but also could be performed under local retrobulbar anesthesia. To our knowledge, this stepwise microinvasive vitrectomy-assisted PKP method has not been reported previously in the medical literature.

The novel procedure we have proposed would ensure the safety and the stability of all open-sky-related procedures during PKP. The anterior chamber is open for a sustained period during the removal of the pathological cornea. During this phase of the surgery, the vitreous pressure would fluctuate greatly, so a stepwise microinvasive anterior segment vitrectomy can be crucial to stabilizing the vitreous pressure. In addition, the degree and duration of the vitrectomy can be well controlled by the surgeon, who can assess the vitreous pressure by observing the position of the lens-iris diaphragm. The ideal state for vitreous pressure is manifested during the opening period, the iris does not prolapse outwards through the gap caused by the incision, and after the entirety of the pathological cornea has been removed, the lens or the IOL does not gradually prolapse outwards [19] (Fig. 3c, d). Moreover, because the vitrectomy can be performed at any stage of the procedure, the stability of the anterior chamber can be maintained, and the subsequent suturing process can be completed successfully.

In this case series, the lens or IOL always stayed in place without prolapsing. The following are some guidelines for applying this novel method. First, to prevent vitrectomy trocar insertion difficulties caused by a reduction of the vitreous pressure, the vitrectomy trocar should be inserted before opening the anterior chamber. In addition, the vitrectomy should not be started before the recipient cornea has been trephined, because decreased vitreous pressure caused by the vitrectomy will make it difficult to place the vacuum trephine in a position that will enable precise trephining. Besides, the anterior vitrectomy is a slow, stepby-step process, and the vitreous pressure should be evaluated in real time by observing the position of the lens-iris diaphragm. Moreover, the vitreous pressure should be kept within a suitable range to prevent the eyeball from collapsing as a result of hypotonia oculi, which is also a risk factor for choroidal detachment and hemorrhage.

Compared to the conventional PKP, the extra iatrogenic trauma in this novel procedure is the microinvasive vitrectomy which is a procedure considered minimally invasive by several researchers [20-22], and our preliminary clinical data show no relative intraoperative and postoperative complications. The vitrectomy we performed is a microincision anterior vitrectomy surgery with 25-gauge $(G)$ or 23-G instruments. During the procedure, only the anterior vitreous was excised minimally without infusion of balanced salt solution, which had little influence on the whole vitreous and retina structure. Corneal opacification can, to some extent, make it difficult to see the vitrectomy cutting head, so microinvasive vitrectomy should be performed carefully. This may represent an important difference between the proposed procedure and traditional vitrectomy. All the patients should undergo a B-scan ultrasonographic examination before and after the surgery to ensure that there is no proliferative vitreoretinopathy, retinal detachment, or vitreous hemorrhage. In addition, the use of a longer vitrectomy cannula is recommended to ensure that the cannula tip and vitrectomy cutter can safely enter the vitreous cavity. During the vitrectomy, the vitreous cutter was perpendicular to the sclera and inserted vertically $6-10 \mathrm{~mm}$ into the center of the vitreous cavity to guarantee that only the anterior and center of the vitreous would be excised and that neither the posterior lens capsules nor the surrounding retinal tissues would be damaged.

In our results, the mean value for postoperative corneal topographic astigmatism was $3.59 \pm 0.98 \mathrm{D}$. This was significantly smaller than the previously reported $5.0 \pm 1.5 \mathrm{D}$ [23]. These results may have been obtained because the IOP was kept stable, and suturing was performed under equable conditions.

It was reported that there is some probability $(33.6 \%)$ of increased IOP after conventional PK 
and that patients with bullous keratopathy, preexisting glaucoma, and surgical indications of trauma are at a higher risk compared to patients with other keratopathy diagnoses $[24,25]$. Postpenetrating keratoplasty glaucoma can result from several factors, such as distortion of the angle with collapse of the trabecular meshwork, postoperative inflammation, the use of corticosteroids, and suturing techniques, etc. [26]. In our case series, none of the patients exhibited increased IOP during the 1-year follow-up, and none had an angle recession or closure according to the results of the postoperative AS-OCT. Moreover, the positions of the irises and of the lenses or IOL were stable. This could also be measured by AS-OCT, because the preoperative CLR value was $0.48 \pm 0.09 \mathrm{~mm}$ and the postoperative value after 3 months was $-0.16 \pm 0.04 \mathrm{~mm} \quad(p<0.0001)$. This result indicates that the lens or IOL was located somewhat posteriorly after surgery and that this had positive effects on maintaining a steady IOP. Here is our analysis. First, our new procedure avoided PVP. The tensions of the lens-iris diaphragm and the lens zonules were well maintained, and this ensured the normal anatomy of the anterior chamber angle and the correct position of the lens or IOL. In addition, after resection of relatively small amounts of the anterior vitreous, the vitreous volume was decreased; therefore, the anterior chamber was deepened allowing for decreased vitreous pressure on the lens-iris diaphragm. Moreover, minimal intraoperative IOP fluctuations contributed to stable and smooth suturing, which minimized the traction of the suture on the anterior chamber angle, where the trabecular meshwork located.

The mean rate of endothelial cell loss 12 months after conventional PKP ranged from $27.7 \%$ to $40.9 \%[27,28]$. In another modified PKP procedure, which changed the open-sky condition to a closed one, endothelial cell loss was almost within the normal range $[15,16,29]$. In all of these procedures, the donor corneal graft had been covered and sutured on top of the recipient bed before all or parts of the recipient cornea were removed from the anterior chamber $[15,16,29]$. The suturing and removal stages should cause some loss of the graft endothelium. In our case series, endothelial cell loss was $22.2 \% 12$ months after surgery, and this was close to the reported base level of conventional PKP [27]. This likely contributed to the absence of obvious endothelium-damaging steps with our method. However, this study has limitations: a relatively small number of cases, higher equipment requirements, and higher skill requirements.

\section{CONCLUSION}

This novel and stabilized PKP procedure, which was performed in conjunction with the stepwise anterior vitrectomy, could become an alternative corneal transplantation procedure, because it effectively avoids PVP during open-sky surgery and significantly increases surgical safety.

\section{ACKNOWLEDGEMENTS}

Funding. This work was supported by Shanghai Scientific and Technical Innovation Plan 2016, experimental animal research project (Project number: 16140900900); and the Excellent Academic Leader Training Program of Shanghai Municipal Health System (2017BR060). The Rapid Service and Open Access Fees were funded by the project funding of Excellent Academic Leader Training Program of Shanghai Municipal Health System (project number: 2017BR060).

Authorship. All named authors meet the International Committee of Medical Journal Editors (ICMJE) criteria for authorship of this article, take responsibility for the integrity of the work as a whole, and have given their approval for this version to be published.

Authors' Contributions. Author contributions: Design of the study (Yanlong Bi); conduct of the study (Xinyu Huang); collection, management, analysis, and interpretation of data (Qi Zhou and Sangsang Wang); and preparation, review, or approval of the article Juan 
Zhang and Guozhen Niu). All authors read and approved the final manuscript.

Disclosures. Xinyu Huang, Qi Zhou, Sangsang Wang, Juan Zhang, Guozhen Niu, Yanlong Bi have nothing to disclose.

Compliance with Ethics Guidelines. This study was approved by the ethics committee of Tongji Hospital, Tongji University School of Medicine, and adhered to the tenets of the Declaration of Helsinki. Written informed consent was obtained from the patients for publication of this article and any accompanying images.

Data Availability. The datasets used and/or analyzed during this current study are available from the corresponding author on reasonable request.

Open Access. This article is distributed under the terms of the Creative Commons Attribution-NonCommercial 4.0 International License (http://creativecommons.org/licenses/ by-nc/4.0/), which permits any noncommercial use, distribution, and reproduction in any medium, provided you give appropriate credit to the original author(s) and the source, provide a link to the Creative Commons license, and indicate if changes were made.

\section{REFERENCES}

1. Tan DT, Dart JK, Holland EJ, et al. Corneal transplantation. Lancet. 2012;379:1749-61. https://doi. org/10.1016/S0140-6736(12)60437-1.

2. Kymionis GD, Mikropoulos DG, Portaliou DM, et al. New perspectives on lamellar keratoplasty. Adv Ther. 2014;31:494-511. https://doi.org/10. 1007/s12325-014-0121-0.

3. Tan JC, Holland SP, Dubord PJ, et al. Evolving indications for and trends in keratoplasty in British Columbia, Canada, from 2002 to 2011: a 10-year review. Cornea. 2014;33:252-6. https://doi.org/10. 1097/ICO.0000000000000066.

4. Park CY, Lee JK, Gore PK, et al. Keratoplasty in the United States: a 10-year review from 2005 through
2014. Ophthalmology. 2015;122:2432-42. https:// doi.org/10.1016/j.ophtha.2015.08.017.

5. Chronopoulos A, Thumann G, Schutz J. Positive vitreous pressure: pathophysiology, complications, prevention, and management. Surv Ophthalmol. 2017;62:127-33. https://doi.org/10.1016/j. survophthal.2016.10.002.

6. Figueiredo GS, Kolli SS, Ahmad S, et al. UrretsZavalia syndrome following penetrating keratoplasty for keratoconus. Graefes Arch Clin Exp Ophthalmol. 2013;251:809-15. https://doi.org/10. 1007/s00417-012-2148-8.

7. Konomi K, Shimazaki J, Shimmura S, et al. Efficacy of core vitrectomy preceding triple corneal procedure. Br J Ophthalmol. 2004;88:1023-5. https://doi. org/10.1136/bjo.2003.033902.

8. Maharajan VS, Dua HS, Maharajan P, et al. Role of choroidal drainage in therapeutic keratoplasty. Cornea. 2002; 21:384-7. https://journals.lww.com/ corneajrnl/toc/2002/05000.

9. Chu TG, Green RL. Suprachoroidal hemorrhage. Surv Ophthalmol. 1999;43:471-86. https://doi.org/ 10.1016/S0039-6257(99)00037-5.

10. Glazer LC, Williams GA. Management of expulsive choroidal hemorrhage. Semin Ophthalmol. 1993;8:109-13. https://doi.org/10.3109/08820539 309060218.

11. Schutz JS, Mavrakanas NA. What degree of anesthesia is necessary for intraocular surgery? It depends on whether surgery is "open" or "closed". Br J Ophthalmol. 2010;94:1400-13. https://doi.org/ 10.1136/bjo.2008.152660.

12. Wang X, Dang GF, Li YM, et al. General anesthesia versus local anesthesia for penetrating keratoplasty: a prospective study. Int J Ophthalmol. 2014;7:278-82. https://doi.org/10.3980/j.issn.22223959.2014.02.15.

13. Zhou YL, Tong Y, Wang YX, et al. A prospective, randomised, double-masked comparison of local anaesthetic agents for vitrectomy. Br J Ophthalmol. 2017;101(8):1016-21. https://doi.org/10.1136/ bjophthalmol-2016-309780.

14. Mannan R, Sharma N, Pruthi A, et al. Penetrating keratoplasty for perforated corneal ulcers under topical anesthesia. Cornea. 2013;32:1428-31. https://doi.org/10.1097/ICO.0b013e3182a27939.

15. Chen W, Ren Y, Zheng Q, et al. Securing the anterior chamber in penetrating keratoplasty: an innovative surgical technique. Cornea. 2013;32:1291-5. https://doi.org/10.1097/ICO.0b013e31829954c5. 
16. Can E, Başural E, Genç ÇD, et al. Anterior chamber stabilization in combined penetrating keratoplasty with scleral-sutured posterior chamber intraocular lens implantation. Cornea. 2015;34:985-90. https://doi.org/10.1097/ICO.0000000000000469.

17. Noh HJ, Kim ST. Combined treatment of phacoemulsification and single-port limited pars plana vitrectomy in acute angle-closure glaucoma. Int J Ophthalmol. 2019;12:974-79. https://doi.org/10. 18240/ijo.2019.06.15.

18. Kopecky A, Nemcansky J. Changes in the anterior segment of the eye following uncomplicated pars plana vitrectomy: a review. Biomed Pap Med Fac Univ Palacky Olomouc Czech Repub. 2019;163:207-11. https://doi.org/10.5507/bp.2019. 014.

19. Gupta PC, Ram J. A classification system of intraocular lens dislocation sites under operating microscopy, and the surgical techniques and outcomes of exchange surgery. Graefes Arch Clin Exp Ophthalmol. 2016;254:2487-8. https://doi.org/10. 1007/s00417-016-3486-8.

20. Liu X, Li M, Cheng B, et al. Phacoemulsification combined with posterior capsulorhexis and anterior vitrectomy in the management of malignant glaucoma in phakic eyes. Acta Ophthalmol. 2013;91(7):660-5. https://doi.org/10.1111/j.17553768.2012.02451.x.

21. Grandinetti AA, Kniggendorf V, Moreira LB, et al. A comparison study of corneal topographic changes following 20-, 23-, and 25-G pars plana vitrectomy. Arq Bras Oftalmol. 2015;78:283-5. https://doi.org/ 10.5935/0004-2749.20150075.

22. Yokota $\mathrm{R}$, Inoue $\mathrm{M}$, Itoh $\mathrm{Y}$, et al. Comparison of microincision vitrectomy and conventional 20-gauge vitrectomy for severe proliferative diabetic retinopathy. Jpn J Ophthalmol. 2015;59:288-94. https://doi.org/10.1007/s10384-015-0396-y.
23. Huang $\mathrm{T}, \mathrm{Hu} \mathrm{Y}$, Gui $\mathrm{M}$, et al. Comparison of refractive outcomes in three corneal transplantation techniques for keratoconus. Graefes Arch Clin Exp Ophthalmol. 2015;253:1947-53. https://doi. org/10.1007/s00417-015-3091-2.

24. Goldberg DB, Schanzlin DJ, Brown SI. Incidence of increased intraocular pressure after keratoplasty. Am J Ophthalmol. 1981;92:372-7. https://doi.org/ 10.1016/0002-9394(81)90527-4.

25. Simmons RB, Stern RA, Teekhasaenee C, et al. Elevated intraocular pressure following penetrating keratoplasty. Trans Am Ophthalmol Soc.1989; 87:79-91. https://www.ncbi.nlm.nih.gov/pmc/ articles/PMC1298538/ (discussion 91-3).

26. Huber KK, Maier AK, Klamann MK, et al. Glaucoma in penetrating keratoplasty: risk factors, management and outcome. Graefes Arch Clin Exp Ophthalmol. 2013;251:105-16. https://doi.org/10. 1007/s00417-012-2065-X.

27. Cheng YY, Visser N, Schouten JS, et al. Endothelial cell loss and visual outcome of deep anterior lamellar keratoplasty versus penetrating keratoplasty: a randomized multicenter clinical trial. Ophthalmology. 2011;118:302-9. https://doi.org/ 10.1016/j.ophtha.2010.06.005.

28. Borderie VM, Sandali O, Bullet J, et al. Long-term results of deep anterior lamellar versus penetrating keratoplasty. Ophthalmology. 2012;119:249-55. https://doi.org/10.1016/j.ophtha.2011.07.057.

29. Arslan OS, Unal M, Arici C, et al. Novel method to avoid the open-sky condition in penetrating keratoplasty: covered cornea technique. Cornea. 2014;33:994-8. https://doi.org/10.1097/ICO. 0000000000000186. 